\title{
Amenity grass seed production in practice
}

\section{A. G. WRIGHT}

K.D. 5.. Ashburton

ABSTRACT. The growing and harvesting of amenity grass seed crops requires special management and also modifications and adjustments to header harvesters for the various cultivars.

Key words: Amenity grass, seed production, seed harvesting, Agrostis ienuis, Agrostis palustris, Festuca rubra. Poa pratensis.

\section{INTRODUCTION}

Many of the characteristics which are required in an amenity grass such as low growth rates and lack of stemminess are incompatible with a potential for seed production. Further, many of the amenity grasses are late flowering and may have a lower seed production potential. Finally, because these species and cultivars are primarily selected for amenity purposes, specialist seed production methods and management are needed.

\section{SEED PRODUCTION}

Seed production can be divided into two main operations: the growing of the crop, and its harvesting.

As with the growing of any other crop, we must first understand the rhythm of the species and cultivar we are growing, and how the plant reacts to physical factors which include:

1. Time of sowing (spring or autumn).

2. Method of sowing (briadcast, spaced rows, conventional drilling).

3. Type, quantity and timing of fertilizer application.

4. Irrigation timing and application.

5. Weed and pest management.
The two vital stages of the growing cycle are (a) when the seedhead is initiated, and (b) flowering.

First, we require the plant to produce the largest seedhead possible and then obtain maximum pollination and seed set. After first establishing the date when each species and cultivar are at these growth stages, we can then manage our crops with fertilizer and irrigation to achieve optimum plant vigour.

\section{ESTABLISHMENT}

Spring sowing red fescue (Fesfuca rubra L.), Poa pratensis L., browntop (Agrostis fenuis Sibth.) and creeping bent (A. palustris L.) gives these crops time to establish strong plants prior to head initiation. Amenity ryegrasses can be either spring or autumn sown. Provided we have irrigation or a good summer rainfall, all these species can be established under a cover crop of linseed, barley or wheat.

\section{Sowing Methods}

Red fescue, Poa pratensis, S50 timothy (Phleum berfolonii DC) and amenity ryegrasses are established as in herbage grass seed production. Rows $36 \mathrm{~cm}$ apart are used in early multiplications and $15 \mathrm{~cm}$ apart for final bulking up, with one to three crops being harvested from each establishment. The very small seeds of browntop and creeping bent mean that very shallow sowing is essential and broadcasting followed by rolling is usually satisfactory. These species should last 3 years or more.

\section{Fertilizer}

Provided a reasonable level of soil fertility is present, only superphosphate should be necessary at establishment and a $\mathrm{pH}$ of 5.6 to 6 is satisfactory. Browntop and creeping bent 
will produce at a lower $\mathrm{pH}$ but respond better to phosphate and nitrogen when the $\mathrm{pH}$ is 5.6 to 6 . Nitrogen will improve seed yields in all species and it should be applied at either pre-head initiation or pre-flowering. Amenity grasses are selected for density, and nitrogen applied at other growth stages will produce excess vegetation. This utilizes nutrients and moisture which are essential for high seed yields and may cause lodging at flowering with drastic reductions in seed yield.

\section{IRRIGATION}

The timing of irrigation coincides precisely with nitrogen application for the same reasons. If overhead irrigation is used it is desirable that it is applied pre-flowering.

\section{Othler management FaCtors}

A paddock selected for amenity grass seed production must be free of all grasses. Other annual weeds can be easily controlled by spraying with $900 \mathrm{ml} \mathrm{MCPA}$ and $180 \mathrm{ml}$ dicamba/ ha.

To maintain low plant density in established crops of $P$ oa pratensis and fescue, inter-row cultivation or band spraying with paraquat is possible. With browntop and creeping bent, ploughing or burning in the autumn will reduce plant population. Plant density can also be kept down by spraying with low rates of herbicides such as dalapon after harvest when any shed seed has chitted. Germination may require an irrigation, as U.K. experience has shown that the chemical must be applied soon after harvest if adult plants are not to be nff ected.

Quantities of nitrogen or water required by the various species will differ with soil type, fertility level, and quantity and spread of rainfall. Time of flower head initiation varies with species: late autumn for red fescue: early spring for Poa pratensis and early-flowering ryegrasses; and mid-spring for late-flowering ryegrasses and S50 timothy.

There are also hybrid grasses like 'Penncross' creeping bent, which is produced by growing three different creeping bent selections in alternate rows, producing a hybrid cultivar suitable for greens on golf courses.
The other amenity species that New Zealand exports in small quantities is yarrow (Achillea millefolium L.). This species is exported to U.K. and Continental countries for use on unstable areas such as autobahn verges. This is the most wind-loss prone of all amenity species, and either deloliation or windrowing is necessary to even up ripening and reduce shattering. Threshing of the crop is easy, but separation in the cleaning area is difficult owing to seed size and weight, and ground speed is slow. I probably put more of this seed over the back of the header than any other crop.

\section{HARVESTING}

Amenity grasses generally require more precise timing for harvesting, and often modifications to the header.

The amenity-type ryegrasses are harvested by normal ryegrass multiplication methods and header settings, and Poa pratensis is similar. Generally, seedheads in these cultivars ripen unevenly, and there are two options: (1) windrow the crop and let it ripen on the ground, or (2) direct-head at a higher moisture content and cool and dry the seed. Both methods remove the risk of seed loss through wind.

The next group are the fescues, browntops, and creeping bents. These cultivars are generally direct-headed, but a peg-tooth drum on the header is necessary to thresh all the seed from the head in one pass. Windrowing or double threshing does work, but the sward is very prone to wind blow.

Wind blow is a high risk with all these cultivars, so harvest timing is crucial.

The other main modifications necessary to the header are to reduce the air flow to the cleaning area and to use fixed riddles for the final cleaning.

\section{CONCLUSION}

There are areas in New Zealand suitable for multiplying amenity grasses. We have combinations of soils, irrigation and climate to multiply most species. Provided stands are managed to produce seed and not turf crops, seed yields equal to anywhere in the world could be obtained. 
There are not as yet any New Zealand cultivars released that are suitable for the premium export market. In fact, the one certified amenity grass $\rightarrow$ browntop - has a certification system which means that a lot of quality seed is exported as uncertified seed, losing färmers and New Zealand many dollars of income.

In establishing these amenity crops it is important to realize that these species can become weeds in conventional crops, and machinery hygiene is a constant problem if these species are not to be allowed to contaminate other crops.
It is vital also to realize that it is necessary to produce top-quality seed.

Our market research must also be good in order to produce the cultivar that the market demands.

The main producer of amenity grass seed is the state of Oregon, U.S.A. Given the cultivars the market demands - cultivars that have reasonable seed-yield potential (and I look to our breeders to remember this) $\rightarrow$ New Zealand can expand both production and exports steadily in the very near future. 